\title{
SOBRE TRES MODELS DE CONEIXEMENT
}

\author{
Josep Maria Terricabras
}

La preocupació pels temes del coneixement travessa la història del pensament occidental. Des de les primeres regles de recerca de Parmènides s'han anat proposant teories i mètodes sobre el coneixement, diversos en l'objectiu, l'abast i la influència.

En les pàgines següents voldtia fer unes consideracions sobre tres d'aquests models de coneixement: en primer lloc examinaré el model que concep el coneixement com un edifici; en segon lloc, el model que es fixa en el coneixement com a mètode interpretatiu; finalment voldria propugnar un tercer model, el del coneixement com a caracterització de casos, que em sembla que tecull els avantatges dels models antetiors i n'esquiva, en canvi, algunes de les dificultats. El tepàs d'aquests models —encara que es tracti d'un esbós ràpid- pot ajudar a descobrir, de rebot, que l'elecció de l'un o de l'altre no és ni una mera casualitat (o necessitat) anhistòticâ, ni un simple tecurs de treball neutral i sense cap transcendència. De fet, els models que inspiren les recerques humanes responen sempre a unes determinades preconcepcions ideològiques. Examinar-los ajuda a posar-les de manifest. 


\section{EL CONEIXEMENT COM A EDIFICI}

Aquest és un dels models més estesos i més influents en la història de l'epistemologia. Molts pensadors — tant alguns de tarannà especulatiu com d'altres d'orientació més positiva i científica-m han compartit la necessitat $i$ el desig de construir el coneixement humà sobre alguna base absolutament fiable. Justament el caràcter absolut que s'exigeix a aquesta base ha portat també a pressuposar que la base havia de ser última, que només és absolut allò que és també últim. No és gens estrany que una base així es busqués en la filosofia i que els flòsofs participessin activament en la recerca. I és que la preocupació per allò que és absolut, últim, radical, és especialment intensa i habitual en molts filòsofs especulatius que pensen que la filosofia, per principi, no pot pas quedar satisfeta amb allò que normalment satisfà l'home del carrer, capaç d'acontentar-se amb certeses i coneixements parcials $i$ telatius, adquirits moltes vegades per mitjans ben poc crítics. Fins i tot eils diversos resultats de les ciències han de ser qüestionats i refonamentats, perquè no n'hi ha pas prou amb la solidesa obtinguda en àrees tan testringides del coneixement $\mathrm{i} / \mathrm{o}$ tan condicionades pels fenòmens canviants de la naturalesa. I és que aquests filòsofs pensen que si es pot anar més enllà en el coneixement, s'hi $b a$ d'anar. Per a ells, la filosofia ha d'anar més fluny que els altres, ha de fer més passos que ells; i els ha de fer per la senzilla raó que es poden fer; només quan s'hagi fet el que s'havia de fer -que és el que es podia fer-, només aleshores s'haurà arribat al final del camí, a l'horitzó últim des del qual es poden entendre —com qui diu, es poden atalaiar - tots els passos anteriors, els quals només es poden apuntalar, justificar definitivament, des d'aquesta base última, absoluta.

És ben normal que l'home no especulatiu no comparteixi aquest plantejament, i que l'exigència metafísica d'anar sempre més liuny, més enilà, tingui per ell, més aviat, un cert regust de pensament olímpic (altius, fortius, citizs), pensament que potser admixa, però que no pot ni vol imitar. $Y$ és que l'home no especulatiu només cultiva el coneixement que de fet necessi. ta -que no vol dir que només cultivi coneixements útils-, i es manté disposat a buscar nous coneixements quan els necessiti. Ell no accepta —amb tota la taó- que «poder» impliqui «haver de», que «poder anar més lluny» impliqui «haver-hi d'anar». En té prou d'anar tan Iluny com li cal; quan ha arribat a lloc, es detura. Ja ho sap que podria continuar caminant, però no veu quina gràcia tindria fer-ho, quan ja ha arribat allà on anava. L'especulatiu, en canvi, com que sap que es pot anat més lluny, prossegueix el camí. Es pot dir que no va a cap lloc concret; simplement va més lluny, vers la fi del camí, però, estrictament parlant, no sap pas quin és el lloc que hi ha a la fi del camí. (D'aquí que els metafísics espe* 
culatius no puguin, pròpiament, "teconèixer» el $110 c$ al qual axtiben com a l'últim lloc del camí. I, quan s'hi queden, ho han de justificar demostrant que ja no es pot anat més enllà.) Aquest filòsof, doncs, no va tan lluny com li cal, sinó tan Iluny com és possible, és a dir, com cal. Així, no parteix pas de cap situació real que li creï necessitats reals, sinó que parteix de possibilitats lògiques que li creen necessitats metafísiques. (Ara bé, del fet que l'especulatiu vagi sempre «més enllà», no se'n pot pas concloure que la seva exploració sigui més desinteressada, més gratuita, que la dels altres. Més aviát sembla que sigui a l'inrevés. Perquè, ¿com s'ha de lligat la gratuiitat amb l'obligació que ell imposa? D'un poeta, per exemple, sí que es podria dir que sovint fa excursions conceptuals gratuites: ho fa quan va allà on vol $\mathrm{i}$, fins $\mathrm{i}$ tot, quan s'adona que ha artibat on no pretenia, on mai no hauria gosat anar. Però, si quan se n'adona se'n penedeix, aleshores és que ja no fa versos, sinó moral o, si es vol, versos morals; i aquests ja no són gratuïts.)

Segons el filòsof especulatiu, l'actitud que ell manté revela un tret absolutament distintiu - $-i$, per tant, irrenunciable-- de l'esperit autènticament filosòfic: el desig d'arribar sempre al descobriment de les raons i de les causes últimes. El que segons ell cal és arribar al reducte últim del coneixement, al seu nucli, a la seva mateixa essència. L'especulatiu pensa que (el coneixement de) l'essència del coneixement gatanteix (el coneixement correcte de) tot coneixement possible. Sembla clar, però, que així queda atrapat en una paradoxa sense escapatòria: perquè, que s'ha arribat a l'essència del coneixement només se sap gràcies a un coneixement que o be pertany o bé no pertany a l'essència a la qual s'ha arribat. Si aquest coneixement és de l'essència del coneixement, vol dir que allò que no es té i que es busca (l'essència del coneixement), és quelcom que ja es té i que d'alguna manera s'ha de pressuposar com a posseït: en aquest cas, conèixer l'essència del coneixement to és pas arribat a un coneixement nou. Si, en canvi, aquest coneixement no és de l'essència del coneixement, aleshores haurem de reconèixer que l'anomenada essència to és l'essència de tot coneixement possible. Així doncs, voler arribar a conèixer l'essència del coneixement és emprendre una tasca impossible: perquè o bé s'ha de pressuposar ja el coneixement de l'essència o bé s'ha d'afirmar que aliò a què s'arriba no és l'essència. (De fet, ha estat en bona part la voluntat d'evitar les dificultats d'una formulació explícita de l'essència del coneixement el que ha portat sovint a recórrer a la intuïció, en mil versions difetents.)

També hi ha filòsofs, però, que, tot volent donar un to més científic a Ia seva activitat, renuncien a buscar una essència pròpiament dita del coneixement, $i$ accepten, en 1 loc d'ella, un tipus de coneixement com a coneixement per excellència, com a paradigma de tot coneixement (el co- 
neixement matetnàtic, per exemple, o bé el físico-matemàtic). Aleshores tots els altres coneixements - per una mena de (de)gradació platònicaadquireixen i mantenen la seva condició en funció de la seva relació amb el paradigma, de manera que es va esvaint la seva capacitat i credibilitat cognoscitiva a mesura que se'n van allunyant. Això explica que, en aquesta concepció del coneixement, hi hagi «coneixements» que, per més que ho pretenguin, no puguin ser considerats com a tals, sinó que hagin de ser desemmascarats com a pseudo-coneixements. Observem, petò, que els pen. sadors que procedeixen així, l'únic que fan és renunciar a "descobrir» l'essència filosòtica del coneixement, però que en canvi continuen propugnant l'existència d'una essència del coneixement.

Així doncs, tots els pensadors essencialistes - de l'orientació que siguin- accepten l'existència d'alguna base sólida, segura, última, per al coneixement humà. I acostumen a trobar-la en certs conceptes bàsics o termes que s'expressen a través d'essències i de definicions. Si s'examinen, però, aquests intents definitoris tal com s'han anat produint al Ilarg de la història del pensament, hom s'adona que o bé són excessivament amples - bé desconsideradament estrets. I és que, quan es vol definir el coneixement de manera que la definició abraci $\mathrm{i}$ inclogui qualsevol ús possible de «coneixement», s'han d'oferir trets tan generals del coneixement, que la caracterització que s'obté difícilment pot fer la funció d'una definició, és a dit, d'una de-limitació que discrimini entre aquells casos que cauen sota la definició $\mathrm{i}$ aquells que no hi cauen. La definició no defineix $i$, per tant, no resulta operativa. Quan, en canvi, no es vol renunciar a una definició conceptual realment operativa, s'acaba formulant una definició que no fa sinó accentuar - de manera dogmàtica $i$ parcial -algun aspecte del coneixement per sobre dels altres. (Exemples magnífics d'això es troben constantment en els diàlegs de Plató, i concretament en el mateix Teetet, que s'ocupa de 'essència del coneixement.) Que les definicions essencialis. tes no serveixen --per massa vagues o massa parcials--, ho testimonia la gran quantitat existent de defnicions essencials sobre els mateixos conceptes, sense que hi hagi criteris definitius per a decidir en favor de l'una o de l'altra. En això rau justament l'anomenat «escàndol de la filosofia».

De fet, el gran perill de l'essencialisme - perill essencial- és que, tot volent anar sempre més enllà dels fets, acaba oblidant-los. Oblida que hi ha gent que cultiva, dóna i rep coneixements que no encaixen amb les preconcepcions o amb les definicions que es donen; perquè els coneixements amb què viu la gent - coneixements que poden ser investigats $\mathrm{i}$ discutitsexisteixen realment. Quan s'oblida això, el coneixement ja no s'ocupa de comprendre la realitat, sinó de comprimir-la. I és que l'afany definitori 
només té sentit quan és metodològic, quan assumeix, en la seva pròpia. formulació, la seva limitació. Si el que fa una definició és posar límits, ella. mateixa ha de ser sempre limitada. No té cap sentit donar una definició, posar un límit, a tot -i menys encara al Tot. Quan s'oblida tot això és quan s'acaben fent definicions inútils, o bé definicions dogmàtiques, ideotògiques.

Sembla clar que l'intent constantment repetit de voler aprofundir en les arrels últimes del coneixement, de voler definir el coneixement últim -que aleshores seria el primer, el més cert de tots-, s'inspira en un model aparentment ben «natural», però, de fet, enormement perillós: es tracta de l'analogia del coneixement amb un edifici. Sabem que si els fonaments d'un edifici són sòlids, tot l'edifici s'aguanta, però que si els fonaments són de sorra, tot l'edifici s'en-sorra. Pet analogia amb això, es parla de l'edifici del coneixement: si els coneixements bàsics, fonamentals, són sòlids, tot l'edifici ho serà. Qui va donat un impuls decisin a aquest model i a aquesta forma de pensar en l'època moderna fou Descartes. Potser això sol justifica que se thagi de considerar — per bé i per mal- el «pare de la filosofia moderna». La seva obra i el seu projecte "han fascinat literalment un gran nombre d'autors i de corrents fins als nostres dies. Sovint se li han fet esmenes, retocs i objeccions, però rarament se n'ha quiestionat el plantejament, que ha estat considerat per molts com a bàsicament correcte. És de Descartes que s'ha heretat el desig de trobar una fonamentació última que permeti, per un procés deductiu d'inspiració matemàtica, artibat a la construcció d'un edifici de coneixements sòlids i deffnitius. Et propòsit de Descartes és precisament antiescèptic $i$ no tendeix «a altra cosa que a trobar la seguretat i a rebutjar la terra movedissa i la sorra, per a trobar la toca o l'argila». Amb ell comença, doncs, el fonamentalisme en les teories del coneixement modernes, fonamentalisme que és alhora un reduccionisme, tant si es revesteix d'essencialisme metafísic com d'axiomatisme científic. (No em puc estar de trobat un cert regust religiós, de «principi i fonament» ignasià, en el projecte de Descartes.) Aquest fonamentalisme epistemològic ha tingut molt de predicament a Europa. El fet és que el naixement i el creixement de tots els camps del saber humà - tal com s'experimenten en els segles Xvin i XIX- van acompanyats d'una gran precupació pels fonaments de les diverses ciències. Més encata: la crisi que moltes d'aquestes ciències experimenten poc després en els propis fonaments no és vista com una crisí del fonamentalisme, sinó més aviat

1. Cf., per exempie, la quarta part del Discurs del mètode.

2. R. Descartes, Discurs del mètode, trad. de I. Xirau, Ed. Barcino, Barcelona, 1929 , p. 38 (cap al final de la $3 a$. part). 
com una crisi fonamental, a la qual es reacciona reforçant precisament els fonaments.

El pensador essencialista, però, allò que busca no són pas simplement els fonaments d'una determinada ciència, sinó els fonaments del coneixement en general, de tot coneixement, i està buscant, per tant, uns fonaments que aguantin qualsevol edifici possible. La veritat és que no resulta gens clar ni què vol dir buscar uns fonaments d'aquesta mena (els fonaments només tenen sentit en funció d'allò que han d'aguantar), ni què vol dit que només eliss poden oferir certesa absoluta (la certesa absoluta vindrà normalment de fonaments absolutament certs, no de fonaments absoluts). No és pas gens estrany que aquest tipus de fonament sovint només s'hagi sabut trobar en Déu o bé en alguna altra realitat (la lògica, la intuïció, el ser) que, d'una forma divinament laica, també pugui ser «causa sui». El fonament últim absolut —concret i alhora universalment vàlid- és impossible de trobar. El que sembla més plausible és inventar-lo, que és el que, en el fons, ban fet - tant si ho teconeixen com si no- la tradició essencialista i la fonamentalista. Tal com ho han fet també la mitologia i la literatura de totes les èpoques. Que aquest invent sigui útil en el camp epistemoIògic, per a la fonamentació concreta de coneixements concrets, no sembla que vingui avalat ni per l'experiència històrica ni per la viabilitat metodològica de la proposta.

Em temo que en aquest cas l'argumentació fonamentalista ha sofert una ensopegada lògica força freqüent en la reflexió filosdfica: el problema s'ha plantejat bé, la solució, però, s'ha mal interpretat. Perquè el fonamentalisme ha vist bé que tot coneixement necessita fonaments. Però aleshores s'ha llançat, erròniament, a buscar els fonaments de tot coneixement. I és que, seguint Bambrough, podem dir que «encara que tot coneixement necessiti fonaments, no hi ha cap fonament que tot coneixement necessiti». ${ }^{3}$

\section{EL CONEIXEMENT COM A INTERPRETACIO}

Aquest segon model too té —com tenia l'anteriot- la pretensió de ser el model del coneixement, sinó que pretén només de ser un model, especialment aplicable a les anomenades "ciències humanes». Quan es pensa en el coneixement per analogia amb un edifici, es volen trobar els elements bàsics, fonamentals, sobre els quals es puguin basar tots els altres coneixements possibles. Ara, en canvi, es pensa en el coneixement com en un

3. R. Bambrough, «Foundations», a Analysis, 30 (1969-70), 197. 
conjunt d'indicis que s'han d'interpretar; per això es gira la mirada cap a dades que precisament no són centrals, sinó marginals, però que poden ser considerades com a reveladores, perquè a partir d'elles — si se saben entendte i interpretar- es pot arribar a una realitat més enllà d'elles, que estava oculta $\dot{i}$ que es manifesta a través dels indicis. Els indicis, per tant, només interessen com a símptomes, com a senyals, d'aquesta altra realitat que, en darrer terme, és la que resulta realment important $\mathrm{i}$ interessant.

Així com vèiem que, en l'època moderna, Descartes fou un impulsor clau del model del coneixement com a edifici, podem dir que Galileo ha estat una figura clau en el model del coneixement com a interpretació d'indicis. Recordem la imatge que usa al començament d'un dels seus llibres més cèlebres:

«La filosofia està escrita en aquest liibre grandíssim que tenim obert davant els ulls, és a dir, l'univers; però aquest llibre no es pot entendre si abans no s'aprèn a entendre la llengua, a conèixer els signes, en què està escrit. Està escrit en llenguatge matemàtic $i$ els seus signes són triangles, cercles $\mathrm{i}$ altres figures geomètriques, sense les quals és impossible d'entendre ni una paraula; sense ells és com anar giravoltant inútilment en un la-

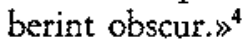

És la metodologia empírica impulsada per Galileo la que ara servirà de punt de referència al coneixement indiciart, ja que aquest, pel fet de moure's bàsicament en l'àmbit de les ciències humanes, no pot recolzar-se en el mètode axiomàtico-deductiu de la matemàtica. La realitat és com un liibre, com un missatge xifrat, i només es pot entendre si se n'entén el codi, si se sap «llegir», interpretar. Aquest mètode es pot illustrar amb P'ajut de casos molt diversos, perquè els indicis poden portar a descobrir l'autenticitat d'una obra d'art (Morelli), o l'origen inconscient d'un trastorn (Freud), el sentit correcte d'un text (en el treball de qualsevol hermeneuta), o el culpable d'un crim (Sherlock Holmes). ${ }^{5}$ L'esquema bàsic d'aquest model sembla l'esquema efecte-causa: els simptomes que es coneixen, els senyals, són efectes d'una causa no manifesta però directament connectada amb ells, de manera que a través d'ells —entenent-los, interpretant-los, refent o desfent els passos en què s'han originat- es pot arribar a descobrir Ia causa, allò que els ha provocat. Les activitats que usen aquest

4. G. Galilei, Il Saggiatore, ed. de L. Sosio, Milà, 1965, p. 38.

5. Sobre el paradigma indiciari del coneixement $c f$, per exemple, C. Ginzburg, «Spie. Radici di un paradigma indiziario», dins Crisi della ragione, ed. d'A. Gargani, Einaudi, Torí, 1979, pp. 59-106. 
model es concentren sempre en la solució de casos concrets; això sembla fer impossible que s'arribi a resultats científicament rellevants, els quals són sempre generals o generalitzables. Fins a quin punt això és així, ho veurem més endavant. El que sí és cert és que el coneixement indiciari vol almenys acostar-se al rigor metodològic galilieà.

Abans d'entrar a fons en la crítica d'aquest model - i com una primera aproximació- em sembla que seria bo d'adonar-se que el model indiciari és un model amplíssim que aplega sota un mateix tètol casos molt diversos. Aquest punt és important precisament perquè ens trobem davant d'un model que accentua la importància de les diferències entre casos particulars, però que després sembla esborrar aquestes diferències tot destacant el tret essencialment comú que hi ha en tots els casos: es tracta de coneixement indirecte, indiciari, conjectural. ${ }^{6}$ Aquesta generalització té l'avantatge - -gaitebé com totes les generalitzacions- de recordar-nos un tret bàsic del coneixement humà: que és conjectural. Alhora, però, passa per alt distincions importants, per exemple entre diversos tipus d'indicis o entre «conjectura» i «coneixement indirecte».

Si els casos concrets són importants, cal demostrar que ho són i com ho són. És en aquest sentit que voldria examinar ara dos casos concrets de coneixement indiciari que, malgrat coincidències evidents, manifesten diferències força significatives. Perquè eis mètodes de Sherlock Holmes i d'Hercule Poirot exemplifquen la mar de bé dues mentalitats i dos estils diversos.

\subsection{El mètode de Sherlock Holmes}

L'obra en què apareix per primera vegada Sherlock Holmes data del 1887 (A. Study in Scarlet). De seguida es pot veure que el personatge porta a sobre les credencials positivistes. Moit significativament, Conan Doyle presenta el personatge en dos capítols diferents, ${ }^{7}$ i en dedica també dos a The Science of Deduction. ${ }^{8}$

Ens presenta Holmes treballant en el laboratori de química de l'hospital. Es tracta d'un home dotat de great powers, ${ }^{30}$ que, quan no està

6. Cf. ibid., per exemple, p. 71 .

7. Cf. «Mr. Sherlock Holmes», cap. 1 de 1a 1a. part d'A Study in Scarlet, i cap. 1 de The Hound of the Baskervilles.

8. El cap. 2 de ia 1a. part d'A Study in Scarlet, i el cap. 1 de The Sign of Four.

9. Cf. A Study in Scarlet, John Murray, Londres, 1967, p. 9. Data endavant citada SS.

10. Cf., per exemple, The Sign of Four, John Murray, Londres, 1971, pp. 9, 10 i passim. D'ara endavant citada SF. 
ocupat amb cap cas, ha de mantenir l'activitat del seu cervell a base de drogues. "1 És una ment científica, personificació del desapassionament i de l'esperit inquisitiu. "Sembla que té una passió pel coneixement precís $\mathrm{i}$ exacte. 12 $^{12}$ Com que el cervell humà és per a ell com un "petit àtic», ${ }^{13}$ no el vol omplir de cap manera amb fets o amb coneixements inútils; ${ }^{14}$ d'aquí també la seva remarcable ignotància en temes de litetatura, fjlosofia $o$ política; aquesta ignorància es converteix en provocació anticultural quan manifesta, sense cap vergonya, que no coneix ni li interessa gens la teoria copernicana de l'heliocentrisme. ${ }^{15}$

Holmes es considera un consulting detective, ${ }^{15}$ que és una professió que no ha triat, sinó que més aviat ha creat; d'aquí que es consideri, repetidament, «únic en el món». ${ }^{17} \mathrm{La}$ modèstia, certament, no és el seu fort. ${ }^{18}$ Considera molt inferiors tant el Dupin d'Allan Poe com el Lecoq de Gaboriau. ${ }^{19}$ Holmes, en canvi, sí que és un specialist in crime, ${ }^{20} \mathrm{i}$ és que «jo examino les dades com un expert, i emeto l'opinió d'un especialistas., És l'autor de diverses monografies, sempre sobre qüestions altament tècniques $\mathrm{i}$ especialitzades, que ell, amb afectada indiferència, anomena «el meu bobbys: 22 monografies sobre la distinció entre les cendres de diversos tabacs, sobre el seguiment de petjades (la branca, que ell anomena «art», més important i més negligida de la ciència de la detecció), ${ }^{23}$ sobre la influència que té cada ofici en la forma de les mans. ${ }^{24}$

Segons Holmes, «la investigació detectivesca és, o hauria de ser, una ciència exacta, i hauria de ser tractada de la mateixa manera freda i desapassionada» ${ }^{25} \mathrm{I}$ exigeix les tres qualitats següents del detectiu ideal: poder d'observació, poder de deducció i coneixement. ${ }^{26}$ És ben clar què vol dit

11. Cf. ibid., pp. 9, 10, 17.

12. SS, 11.

13. SS, 18.

14. SS, 19.

15. SS, 18.

16. SS, 23.

17. Cf. SS, 23; SF, 10; The Hound of the Baskervilles, John Murray, Londres, 1971, pp. 7-8. D'ara endavant citada HB.

18. Ct. SF, 12; $\mathrm{HB}, 2$.

19. SS, 25 .

20. $\mathrm{HB}, 5$.

21. SF, 11.

22. SF, 13.

23. SS, 139.

24. SF, 12-13.

25. SF, 11; cf. SS, 42.

26. $\mathrm{SF}, 12$. 
amb les dutes primeres qualitats, que són independents i s'han de posseit, per tant, cadascuna pel seu compte. ${ }^{27}$

Pel que fa al poder d'observació, cal saber apreciar la importància dels petits detalls. ${ }^{28}$ «El món és ple de coses òbvies que ningú mai no observa ni per casualitat.» ${ }^{29}$ (Aquest és justament el retret que li fa al seu ajudant Watson: «Vostè mira, però no observa.») ${ }^{30}$ Aquestes observacions han de ser precises i minucioses; per això Holmes usa lents convexes, ${ }^{31}$ lupa i cinta mètrica. ${ }^{32}$ En plena acció, fa pensar en un «gos guineuer», ${ }^{33}$ amb una capacitat infinita a l'hora de fxxar-se en les coses. ${ }^{34}$ La primera qualitat d'un detectiu ha de ser la seva capacitat per a veure els fets, encara que es presentin disfressats. ${ }^{35}$

A més d'això, però, cal tenir poder de deducció. Perquè, a partir dels fets observats, no s'ha pas d'endevinar tes, sinó que es pot procedir ja a fer grans inferències inductives que seran, és clar, més o menys probables. ${ }^{36}$ (A vegades, només una o dues indicacions li serveixen ja de base per a diverses deduccions. $)^{37}$ Aquestes inferències es fan de manera analítica, anant dels efectes a les causes, raonant endartera com qui diu. ${ }^{38}$ I és que la vida es pot llegir com un Ilibre..$^{39}$, Qui estigui entrenat en l'observació i en l'anàlisi no es pot pas equivocar; les seves conclusions seran tan infalibles com les proposicions d'Euclides. «Així, tota la vida és una gran cadena, la naturalesa de la qual és coneguda tan bon punt es mostra una sola de les seves anelles. $1^{40}$ L'exclusió de les diverses hipòtesis acaba portant, necessàriament, a aquella que explica els fets. ${ }^{41}$ Sovint, però, el descobriment d'aquestes cadenes lògiques exigeix una gran concentració de

27. $\mathrm{SF}, 13-14$.

28. SF, 13.

29. $\mathrm{HB}, 28$.

30. «A Scandal in Bohemia», dins The Adventures of Sherlock Holmes, John Murray, Londres, 1971, p. 3.

31. $\mathrm{SF}, 15 ; \mathrm{HB}, 2$.

32. SS, 37 .

33. Ibid.

34. Ibid.

35. $\mathrm{HB}, 152$.

36. $\mathrm{SF}, 16 ; \mathrm{HB}, 35$.

37. Cf., per exemple, HB, 3 i 35 ; tot i que aquestes deduccions no sempre són ben correctes: cf. $\mathrm{HB}, 6$.

38. SF, 11; SS, 138.

39. Cf. SS, 22, on es parla d'un article de Holmes en el diari amb el significatiu titol "The Book of Life».

40. SS, 22; cf. SS, 141.

41. SS, 139; SF, 14. 
pensament, que Holmes afavoreix tot creant al voltant seu una atmosfera concentrada. ${ }^{42}$

Tot això podria semblar suficient, però el mateix Holmes exigeix encara una tercera qualitat en el detectiu ideal. ¿En què consisteix, però, aquest altre «coneixement» que demana? ¿No es té prou coneixement amb els dos poders assenyalats? Segons ell, encara cal una «vasta extensió de coneixement exacte», que resulta essencial per al desenvolupament màxim d'això que ara torna a anomenar «un art». ${ }^{43}$ Bàsicament, aquest coneixement sembla consistir en un gran domini de la història del crim, perquè hi ha parentius molt forts entre els diversos casos. ${ }^{44}$ Holmes mateix domina profundament tots aquests "casos parallels». ${ }^{45}$

Heus ací el mètode; es tracta només d'aplicar-lo, ${ }^{46}$ i no es pot pas dir quze sigui tan difícil. Això fa que Holmes no el vulgui explicar massa, perquè els seus raonaments són tan «tidículament simples» que ho podria fer fàcilment qualsevol, ${ }^{47} \mathrm{i}$ aleshores es veuria que ell és «tanmateix, un individu la mar d'otdinari». ${ }^{48}$ Amb aquesta confessió no em sembla pas que Holmes es desdigui de l'actitud presumptuosa que li detectàvern més amunt. Més aviat m'inclino a pensar que ell accepta alhora les dues afirmacions: que el seu mètode és molt simple, però que ell és, ara com ara, l'únic que el domina completament. I és que per més que aquest. mètode es vulgui presentar com una ciència, no s'ha d'oblidar — Holmes no ho oblida- que es tracta d'un art. Això sí, un art que disposa, segons ell, d'un mètode seriós i rigorós, perquè combina la recerca empírica amb la capacitat lògica (d'inducció i de deducció). Recordem que els indicis amb què Holmes treballa són sempre senyals, marques físiques, a partir dels quals ell vol fer la impressió que és possible de treure informació d'una forma quasi automàtica, amb una certa mecànica lògica. Ell, el detectiu positivista, es presenta com el millor perquè presumeix de posseir més informació, més «coneixement» que els altres. En moments menys eufòrics, peró, reconeix que cal tota una vida —i no basta- per a «aprendre on s'ha de mirar i què s'ha de buscat» en cada cas. ${ }^{49}$ Heus ací l'artista.

42. $\mathrm{HB}, 29$.

43. SF, 12; SS, 42; cf. també nota 23.

44. SS, 23. Es interessant observar com en aquest passatge Conan Doyle utilitza l'expressió «a strong family resemblance», que és un concepte que molts anys més tard Wittgenstein fatà cèlebre.

45. SF, 12; SS, 139.

46. $\mathrm{HB}, 3$.

47. Cf. el passatge citat a la nota 30 .

48. SS, 42 .

49. SS, 22 . 


\subsection{El mètode d'Hercule Poirot}

L'obra en què apareix per primera vegada Hercule Poirot data del 1920 (The Mysterious Affair at Styles). Sherlock Holmes ha mort fa temps. Poirot pertany a una altra època i té una altra mentalitat. Ben cert que la modèstia tampoc no és el fort ${ }^{50}$ d'aquest ex-detectiu beiga, ${ }^{51}$ que se sap força superior als detectius en actiu ${ }^{52}$ i molt més sagą̧ que Hastings, el seu amic $\mathrm{i}$ acompanyant en molts casos. ${ }^{53}$ I és que també Poirot es considera un «expert». ${ }^{54}$ De tota manera, un dels trets que millor caracteritza el personatge és justament el fet de presentar-lo en explícita oposició i com una alternativa a Sherlock Holmes. En aquest sentit és molt significatiu el passatge següent:

«"Ordre" i "mètode" eren els seus déus. Tenia un cert menyspreu per l'evidència tangible com ara petjades $i$ cendra de cigarzetes, $i$ sostenia que, considerades en si mateixes, aquestes coses mai no permetrien a un detectiu de solucionar un problema. Aleshores, amb una complaença absurda, tocava el seu cap oviforme i observava amb gran satisfacció: "La veritable feina es fa des de dins. Les petites cèllutes grises - recordi sempre les petites cèllules grises, mon ami".."ss

Poirot, doncs, rebutja expressament allò que per a Holmes resultava fonamental. Així, critica la «idea romàntica que totes les pistes importants hagin de ser infnitesimals», ${ }^{56}$ i es riu del detectiu que -en una evident allusió a Holmes- es converteix en un "gos guineuer humà». ${ }^{57}$ Perquè, per ell, el que és realment important no és «el senyal exterior». ${ }^{56}$ Les veritables pistes no són les puntes de cigarretes o de llumins, sinó les pistes psicològiques. Poirot sap molt bé que posar ordre en un conjunt qualsevol d’objectes, per molt casual que sigui aquest conjunt, és simplement una

50. Cf. The Murder on the Links, Pan Books, Londres, 1971, p. 163. D'ara endavant citada ML.

51. Cf., per exemple, la p. 10 de ML per a la descripció física de Poirot.

52. Ct. ML, 48-51, 135.

53. Cf. The Murder of Roger Ackroyd, Fontana/Collins, Londres, 1974, pp. 196. 197. D'ara endavant citada RA.

54. ML, 214.

55. ML, 10.

56. ML, 52 .

57. ML, 52 i 64; a ML, 101 es parla, en el mateix sentit, d'«un bon gos perdiguer», i a la p. 218 d'un "gos guinezer».

58. ML, 49. 
qüestió d'enginy. ${ }^{59}$ Però no és pas això el que ha de fer un detectiu, ni és aquest el camí de l'èxit. Què cal fer, doncs? «Pensi, amic meu. Ordeni les seves idees. Sigui metòdic. Sigui ordenat. Heus ací el secret de l'èxit.» Ara bé, ¿què és el que s'ha de pensar, sobre quina evidència s'ha de projectar la reflexió?

Per Poirot l'evidència no es fa pas de senyals externs, preferentment minúsculs, que calgui examinar a fons i amb molt dificultat; els seus «fets» són, sobretot, els esdeveniments mateixos, que, per la seva condició d'històrics i temporals, no poden pas tornar a ser viscuts. D'aquí que l'únic accés que s'hi té són les observacions, explicacions, referències $i$ telats que els propis interessats en fan. Tot $i$ que no només compta com a evidència allò que diuen, sinó també molt especialment allò que no diuen, ${ }^{61}$ perquè tots els casos s'assembien en una cosa: que cada implicat té quelcom pex amagar. ${ }^{62}$ I aleshores, fins $i$ tot una observació ben ximple pot revelar la veritat..$^{63}$

El pensament postetior enllaça justament amb totes aquestes evidències, amb observacions que es converteixen en especialment importants i en detonants de tota una cadena de pensaments. ${ }^{64}$ És quan ja s'ha tingut «accés als fets» (i les cometes són de l'original), ${ }^{65}$ que arriba l'hota - per més quse es pugui dir que això és passat de moda- ${ }^{\text {to }}$ de concentrar les cètulules grises i de raonat. ${ }^{67}$

El camí d'aquest raonament és doble: $a$ ) D'una banda, s'ha de descobrir el psycbological background que ajuda a entendre les causes, les taons que han provocat els fets. ${ }^{6}$ A Poirot, que coneix «la ment humana», ${ }^{69}$ li convé de saber quina és, en cada cas, «la interacció de les emocions humanes». ${ }^{70}$ Això pot ajudar també a prevenir altres crims. ${ }^{71}$ D'aquí que ell

59. Hickory Dickory Dock, Fontana/Collins, Londtes, 1979, pp. 12-13. D'ara endavant citada HDD. Aquesta mateixa idea, però exposada encara amb més gràcia, es pot trobar a: G. K. Chesterton, The Innocence of Fatber Brown, Penguin, Harmondsworth, 1973, pp. 116-119.

60. ML, 149.

61. ML, 123; cf. 78 .

62. RA, 71.

63. RA, 197.

64. Cf. Murder on the Orient Express, Fontana/Collins, Glasgow, 1974, pp. 182. 183. D'ata endavant citada $\mathrm{OE}$.

65. ML, 135.

66. HDD, 39; RA, 200.

67. ML, 135, 149; RA, 210.

68. HDD, 38.39.

69. $\mathrm{ML}, 78$.

70. $\mathrm{HDD}, 18$.

71. $\mathrm{HDD}, 33$. 
digui: «Per començar, apliquem la nostra psicologia.» ${ }^{72}$ b) D'altra banda, però, és evident que la investigació no es pot pas basar en imaginacions pròpies o en sentiments, sinó que ha de recórrer a la lògica, ${ }^{73} i$ lògica vol dir necessitat estricta. Aixi, com que "hom ha d'agafar els crims tal com els troba, no tal com hom voldria que fossin», ${ }^{74}$ el que s'ha de fer és explicar lògicament la seqüència dels esdeveniments. ${ }^{75}$ Quan es van eliminant alternatives ${ }^{76}$ i es troba l'uordre propi» dels fets, aquests apunten vers una sola explicació possible. "Evidentment, fets $i$ hipòtesi es corregeixen mútuament: $i$ així com un no es pot aferrar a teories que no vinguint recolzades en els fets, ${ }^{78}$ així també convé girar i regirar els fets per veure sí poden satisfer la teoria. ${ }^{79}$ Per això, quan Poirot té tota l'evidència, s'acomoda, tanca els ulls i comença a pensar. ${ }^{80}$ Tampoc ell no endevina tes, sinó que coneix ${ }^{81} \mathrm{I}$, al final, quan s'han ordenat els fets metòdicament, la solució és tan simple i clara que sembla mentida no baver-la vist abans. ${ }^{82}$

Aquest és el mètode de Poirot. Ell també és acurat i rigorós en les seves deduccions lògiques, i també treballa amb fets, però els seus fets ja no són senyals exteriors, marques físiques, sinó més aviat equivocacions, reaccions, passos en fals, revelacions o mitges veritats, tal com es manifesten en el Ilenguatge i en la conducta de la gent. És evident, doncs, que el mètode de Poitot ha de ser diferent del de Holmes. Perquè una de les lliçons principals de l'anàlisi comparativa d'aquests dos mètodes és que no només ha canviat el concepte de "fet» sinó també el concepte d'«indici». No és pas gens estrany que en la discussió del paradigma indiciati s'usi sovint Holmes com a exemple, i que en canvi no s'usi Poirot. I és que Holmes exemplifica la mar de bé una interpretació dels indicis que després -amb un gir essencialista que recorda trets del primer model assenyalat més amunt- es converteix en paradigmàtica. És ben clar, però, que hi ha altres maneres d'entendre els indicis, perquè hi ha altres maneres d'usarlos. Un bon exemple d'això és justament el cas de Poirot que acabem de veure. Potser serà bo, doncs, de comparar les dues figures després d'baver-

72. ML, 157 .

73. ML, 134, 152 .

74. $\mathrm{ML}, 214$.

75. ML, 157.

76. RA, 202.

77. ML, 121; RA, 211.

78. $\mathrm{ML}, 158$.

79. ML, 163.

80. Cf, per exemple, OE, 182; HDD, 17.

81. RA, 201.

82. OE, 179; RA, 72 . 
les examinat sepatadament, perquè això ens pot introduir en una reflexió crítica més àmplia sobre el model de coneixement que estem considerant.

Per a Holmes, un indici és sempre un senyal d'una altra cosa, és només un mitjà que aporta un coneixement precís però indirecte. El seu esquema. bàsic és l'esquema efecte-causa: a través de l'efecte s'arriba a la causa; l'efecte només té valor en funció del descobriment de la causa. Els objectes. porten missatges que cal desxifrar. Els indicis són la clau, el codi d'aquests. missatges. La vida és un constant exercici semiològic, ple de diminuts significants que amaguen i revelen alhora significats ocults.

Per a Poirot, un indici és un element que esdevé significatiu perquè fa entendre, millor que els altres, el conjunt d'una situació. L'indici no apunta cap a una altra cosa, sinó que apunta alguna cosa, la posa en evidència, la manifesta. L'indici no acaba la seva funció amb la comprensió d'una altra realitat, sinó que és la comprensió del conjunt la que està en funció de la significativitat d'uns indicis determinats. No és a través dels indicis que s'artiba a entendre, sinó gràcies a ells i en estreta connexió amb ells. La vida és un teixit de passions i d'interessos, ple de nusos significatius que concentren característiques, anullen tensions $i$ resumeixen situacions.

Evidentment, I'existència de fum és senyal (indici) d'una altra existència, la del foc. Ara bé, que hi hagi molts papers per terra no és primàtiament senyal d’una altra cosa, sinó més aviat indici de brutícia. Observem, però, que així com el primer exemple té una interpretació rígida, automàtica, ben avalada per l'experiència, el segon exemple admet fàcilment que I'experiència aporti excepcions: perquè els papers per terra no són indici de brutícia en una fàbrica de paper o en una impremta, almenys durant el temps en què les màquines estan treballant. Això vol dir que el punt clau del segon exemple és que un indici ha de ser índex, exponent, d'alguna realitat. Ara bé, aquesta mena d'indicis només es descobreixen si s'abandonen els esquemes rígids i els automatismes interpretatius que pretenen connectar cada senyal amb un significat, i si es substitueixen per una anàlisi precisa $\dot{I}$ extensa alhora de les diverses situacions tal com es doner realment.

I és que convindria afinat força més el model indiciati, perquè: a) no tots els indicis són sempre del mateix tipus, $i$, per tant, b) el paradigma indiciari, tal com es presenta, no és un paradigma operatiu.

La comparació dels casos concrets de Holmes i Poirot justifica per si mateixa l'afirmació feta a a). Hi ha, però, encara una colla de consideracions que podrien resultar fecundes. En primer lloc, convé no portar massa enllà les consideracions d'analogia entre «marca», «senyal», «símptoma» $\mathrm{i}$ 
«indici». ${ }^{83}$ I és que la pregunta que en el fons encara roman sense resposta és: què és un indici? (I aquesta pregunta no té, evidentment, com a única tesposta una definició essencial.) I encara: de què és indici un indici? I per què ho és? Quan en una investigació indiciària s'artiba al desco. briment d'una altra cosa, ¿vol dir això, necessàriament, que la cosa des. coberta és més important que l'indici? ¿Per què els fins han de ser més importants que els mitjans? ¿És el foc, sempre, més important, més valuós, més greu que el fum? Quan s'accepta això, ¿no es fa pas, potser - cosa que també criticàvem en el primer 'model一, perquè sembla que anar al final és sempre anar més lluny i, per tant, sembla millor? Tot això em sembla estretament connectat amb una idea massa present en el pata. digma indiciari: que la realitat a la qual s'artiba és una realitat "més profunda», només aconseguible de manera indirecta a través d'indicis, que són zones privilegiades que permeten de desvetllar, de desxifrar una realitat altrament «opaca». ${ }^{84}$ Que aquesta pot ser una bona manera de descriure alguns dels nostres actes de coneixement, és innegable. Però també ho és que aquesta descripció no pot caracteritzar de cap manera tots els actes de coneixement que legítimament poden ser qualificats d'«indiciaris». Si per a Holmes la realitat és opaca, i s'amaga darrera eis indicis -eils mateixos sovint ben minúsculs, tanmateix-, per a Poirot no hi ha res d'amagat ni d'ocult, tot està perfectament a la vista, i l'únic que cal, és clar, és veure-ho; però això no s'aconsegueix gràcies a un acte d'especial percepció sensible - com en el cas de Holmes-, sinó per una millor comprensió del conjunt. Gairebé podríem dir que, a Holmes, l'ajuda la perspicàcia, i a Poirot, la perspectiva. Així doncs, ni sempre la realitat és oculta, ni sempre el coneixement indiciari és indirecte. El fet que a mi em costi de desco brir o d'entendre una determinada tealitat, no vol dir de cap manera que aqquesta realitat estigués oculta. I si bé és veritat que un aforisme pot fer funcions indiciàries, ${ }^{85}$ també és veritat que l'aforisme -com sovint la paradoxa, o l'aforisme paradoxal- permet una llambregada, directa i vivíssima, sobre una realitat que sempre s'havia vist, però mai sota aquesta nova llum.

Pel que fa a la meva segona afirmació anterior (que el paradigma indiciari, tal com es presenta, no és un paradigna operatiu), ja he dit que no. més era una conseqüència de l'afirmació que acabo de comentar. En la seva formulació més àmplia, el paradigma indiciari no representa un mètode de coneixement particular ni altematiu, sinó més aviat un paradigma

83. El mateix Ginzburg, loc. cit., després de fer referències analögiques (per exemple, pp. 65-66, 69-71), avisa sobre aquest punt (p. 85).

84. Cf. ibid., pp. $65,67,69-70$ i 91 (on diu que aquesta idea acostituisce il nocciolo del paradigma indiziario o semeioticon).

85. Cf. ibid., pp. 91-92. 
indicador d'una colla de maneres de procedir més o menys emparentades entre elles. En el fons, el model indiciari s'installa al bell mig del model científic inductiu, que procedeix per conjectures, i proposa una ampliació en l'aplicació del model de conjectures, servata servanda - sense especificar, però, quines són aquestes servanda. Per això em sembla que l'alternativa no s'ha pas d'establir entre el paradigma indiciari i el paradigma deductiu del coneixement, sinó més aviat entre paradigmes precisos i paradigmes vagues. Fent-ho així es podria veure com alguns membres de la família dels paradigmes indiciaris acaben també aixoplugant-se sota el paraigua $\longrightarrow$ va riablement gran- dels paradigmes precisos. Perquè encara que no sigui ben clar que sigui desitjable que les ciències humanes es regeixin pel criteri rigorós de les ciències empíriques, ${ }^{86}$ tampoc no és gens clar que entre aquestes últimes només hi hagi un criteri de rigor o que sigui desitjable que les ciències humanes renunciìn a qualsevol criteri rigorós.

\section{EL CONEIXEMENT COM A CARACTERITZACIO DE CASOS}

Amb aquest tercer model voldziria insinuar almenys alguna resposta a la qüestió bàsica que es plantegen els altres dos models examinats, tot mirant d'evitar les dificultats en què ells cauen. La pregunta que, de fet, ve a respondre el primer model és: «Què és el coneixement?» I la resposta a la pregunta es concreta en la recerca de definicions, d'allò que, d'una manera absoluta i per sempre, pugui ser l'essència de tot coneixement. Tal com jo ho veig, en aquest model es parteix d'una pregunta correcta, però s'arriba a una tesposta desencaminada $\mathrm{i}$ desorientadora.

El segon model ja no s'ocupa de l'essència del coneixement, sinó que es concreta en aspectes metodològics d'un cert estil de coneixements. La seva pregunta vindria a ser: "Com s'arriba a conèixer en les ciències humanes?» I la resposta ve a fer: a través de l'anàlisi concreta d'indicis en casos concrets i particulars. Tot $\mathrm{i}$ les crítiques ja fetes a aquest model, em sembla que cal destacat-li un mèrit, i és que, malgrat que parteix d'una pregunta excessivament essencialista, arriba a una tesposta que almenys apunta en la direcció correcta.

Per tot això, m'ha semblat que la milior manera de presentar el tercer model seria a base de demostrar que enllaça amb els aspectes que considero correctes de cadascun dels altres dos models: és a dir, amb la pregunta

86. Cf. ibid., pp. 77-78, 92-93. 
del primer $i$ amb la resposta del segon. Val a dir que també aquest model pot invocar alguns ascendents, perquè s'inspira en bona part en les aportacions $i$ els suggeriments de L. Wittgenstein i de J. Wisdom, i en l'obra actual de R. Bambrough. ${ }^{87}$

L'aportació més important d'aquest model és l'afirmació que el coneixement és coneixement de casos, de casos concrets i particulars. Davant les preguntes "què és conèixer?», "quuina és la base última del coneixement?», l'única resposta veritablement correcta és passar a l'examen de casos concrets. Només aleshores es podrà veure quins i quants casos hi ha de coneixement, $i$ quines són les semblances $i$ diferències entre aquests diversos casos; també així es podrà comprovar que hi ha coneixements que parteixen d'uns principis bàsics i d'altres, en canvi, que no. Voldria subratllar que amb això no es pretén pas rebutjar la pregunta, sinó que es vol contestar adequadament. Perquè només l'anàlisi de casos de coneixement ens pot dir què és el coneixement. I és que les preguntes metafísiques no tenen cap interès quan ens conviden a buscar la resposta més enllà dels casos concrets de la tealitat; només en tenen si es responen precisament després d'examinat aquests casos, les seves característiques i propietats, les seves relacions lògiques. Per aquest camí concret semblava que volia anar — però de fet no hi anava- el model indiciari. Aquest model es debatia justament entre l'interès pel cas concret $i$ el remordiment per la manca de rellevància d'uns determinats casos particulars. I és que ja des de Sòcrates sabern que no hi pot pas haver ciència del que és estrictament particular, que el coneixement explicatiu que vulgui ser científic haurà de ser general -que no vol dir abstracte, perquè els coneixements generals s'apliquen a casos concrets. Quan els coneixements explicatius renuncien $\longrightarrow$ no arriben- a la generalització, ja no tenim explicacions científques, sinó mitològiques, màgiques, casuals, que només tenen un interès molt limitat - tot i que potser molt important per a la persona afectada.

Aquest tercer model em sembla que supera clatament aquesta dificultat. Hi ha dues raons bàsiques que abonen aquesta suposició: en primer Iloc, que el model no pretén explicar el coneixement, sinó que només el vol descriute; no es tracta, doncs, d'una altra teoria del coneixement, sinó d'un estadi previ a qualsevol teoria del coneixement que es consideri fonamentada. En segon lloc, que el model no es vol limitar a recollir casos con-

87. A més de les obres ja clàssiques de Wittgenstein i Wisdorn, convé recordar aquí els escrits següents de Bambrough: «Principia Metaphysica», Philosophy, 1964; «Unanswerable Questions», Proceedings of the Aristotelian Society, volum supiementari, 1966; Reason, Truth and God, Methuen, Londres, 1969; «Objectivity and OSjects», Proceedings of the Aristotelian Society, sèrie nova, núm. 72, 1971-72; i l'article citat a la nota 3 . 
crets de coneixement en una mena de collecció sense ordre ni concert, sinó que pretén caracteritzar aquests diversos casos; i això vol dir: descriute les relacions lògiques que hi ha entre les diverses proposicions en què s'expressen els diversos casos i exemples de coneixement. Així doncs, no es tracta d'una investigació empírica de casos, sinó d'una investigació lògica, en què es descriuen les proposicions usades en els casos particulars i se'n fa una caracterització; és a dir, s'examinen i comparen els diversos tipus de coneixement $i$ les taons $i$ justificacions diverses que es donen a favor $i$ en contra. No es tracta, doncs, de plantejar proposicions bàsiques, últimes, ni de prescriure les relacions logiques que hi ha d'haver entre proposicions a fi que siguin «coneixement vertader». Només es vol descriute les proposicions que realment apareixen en els casos conctets $i$ les relacions lògiques que existeixen entre elles. En aquest sentit, es proposa una investigació lògica. D'aquí que el resultat d'aquesta investigació es pugui expressar sempre en forma hipotètica. I és que, quan s'hagin examinat, per exemple, alguns casos en què es fa una verificació empírica, la caracterització que nosaltres en podrem fer no consistirà a dir que en aquells casos s'ha (o no s'ha) verificat això o allò —això és el que diran el̂s qui hagin fet l'experiment-, sinó que només podrem dir que, en aquesta mena de casos, si s'afirma això $i$ això, aleshores s'exigeix que es faci allò o allò altre, i que $s i$ el resultat és aquest o aquell, aleshores s'està (o no s'està) disposat a treure'n aquesta o aquella conclusió.

En sembla que aquest és l'únic camí que garanteix alhora un coneixement concret i rigorós -és a dir, rellevant i generalitzable- de qualsevol àrea del coneixement humà, científica o no científica. $\mathrm{El}$ model, és clar, no aporta solucions ptòpies a les preguntes sobre el coneixement. Es simplement un mètode lògic que descriu $\mathrm{i}$ compara $-\mathrm{i}$ així pasa de manifestles diverses solucions donades pels altres. Però per veure si funciona i com funciona se l'ha de posar a treballar. 